\title{
Facebook: Investigating the influence on consumer purchase intention
}

\author{
James E. Richard \\ Victoria University of Wellington \\ Sarita Guppy \\ Victoria University of Wellington
}

\begin{abstract}
This study investigates the influence of Facebook applications and activities on consumers purchase intention and provide insights into whether consumers take notice of their peer's activity on Facebook and whether that activity influences consumer purchase intention. Regression analyses conducted on the results from a survey of 215 Facebook users suggests that the use of Facebook's like button, location based check-in service and the share button applications positively influence consumers purchase intention. Posting comments on Facebook shows no significant effect on purchase intention. Consequently, marketers should plan to add activities on their Facebook page to help create brand, product or service awareness, and stimulate sales. Shopping through Facebook may well be a key channel of the future.
\end{abstract}

Keywords: Facebook, social networks, applications, sales channel, Internet marketing

\section{Introduction}

Facebook is designed so that users can stay in contact with friends, family, or make new friends through shared-communities. The average Facebook user spends 700 minutes per month online, averaging 130 Facebook friends (Branckaute, 2010). Facebook recently took first place for the most viewed site (Clark, 2010); thus it is an everyday occurrence for users to log into Facebook. Facebook is the way to stay connected 24/7 with the ability to log on through computers, laptops, iPads and mobile devices, and is considered by many businesses as a cost-effective strategy to employ when communicating with consumers (Nelson-Field et al., 2012), consequently the Facebook platform provides benefits to both consumers and businesses.

\section{Literature Review}

Consumers purchase decisions have been studied to a large extent using frameworks from 'offline' and traditional modes of purchasing (van der Heijden et al., 2003). More recently, purchase decisions have been researched in regards to online websites but minimal work has been studied about purchase behaviour through social networking sites. A common theme in current online purchase decision research 
indicates online stores are important and highly visible representatives of the 'new economy' (van der Heijden and Verhagen, 2002). Thus purchasing online is becoming a common way of shopping (van der Heijden et al., 2003).

Trust is a central theme in previous research about online purchase decisions. Weisberg, Te'eni and Arman (2011) investigated the importance of trust in the online environment with respect to past-purchase and intention to purchase in e-commerce. Trust can be defined as 'a psychological state comprising the intention to accept vulnerability based upon positive expectations of the intentions of behaviour of another' (Rousseau et al., 1998). Van der Heijden et al. (2003) identifies two types of issues that affect consumers' online purchases decisions, which are technology and trust. Trust is known to decrease uncertainty in both online and offline shopping contexts, that the immediate physical environment, salespeople and previous customers through word of mouth can create (Weisberg et al., 2011). As a result, trust is an essential element in order for consumers to make purchase decisions. In regards to online purchases, firms' presence through their website and social networking page is the only way for consumers to overcome this uncertainty as the physical shop is replaced by an IT system creating an impersonal storefront (van der Heijden et al., 2003). Personal interactions and offerings, human-computer interfaces, the use of avatars and familiar pay options such as PayPal were identified as potential strategies online firms can use as there is no physical interaction (van der Heijden et al., 2003; Weisberg et al., 2011). In this study, trust is not measured directly against consumer purchase decisions. It is incorporated within each Facebook social plug-in as consumers will unconsciously have a level of trust if they take notice of friends' likes', check-ins, comments and posts. Consequently, in an online environment firms need to communicate to their customers through their website and social networking page to ensure consumers can build trust, and alternatively purchase from the business.

\section{Social Networking}

In the past five years, social networking sites have rocketed from a niche activity into a phenomenon that engages tens of millions of internet users. It has evolved from just being a basic tool for collaborative creations and the sharing of content, to becoming an important part of the media landscape (Singh et al., 2012). Social media is fast becoming the medium of consumer voices. It is estimated that by 2015 social media will become a mainstream mass-media platform that will engage one third of the world's population (Nelson-Field et al., 2012). Social networking can be defined as allowing individuals to construct a public or semi-public profile within a bounded system, articulate a list of other users with whom they share a connection, and view and traverse their list of connections and those made by others within the system (Boyd and Ellison, 2007). There have been many social networking sites over the years, Friendster, one of the first, began in 2002, making use of profiles, public testimonials, comments, and publicly articulated and transferable friends lists (Boyd, 2008a; Wauters, 2011). Friendster was mainly used to meet potential partners, track down old school mates and general entertainment purposes (Boyd, 2008a). In 2003, MySpace was launched, bringing the music scene into social networking, so consumers were interacting with friends as well as consuming popular culture (Boyd, 2008a). Local bands and club owners (particularly indie rock bands) created profiles, which rapidly led them to becoming MySpace’s primary marketing tool (Bosworth, 
2005; Boyd, 2008a). In 2005, the likes of Orkut, Mixi, Hi5, Bebo, LinkedIn, Twitter and Facebook became popular in a range of different countries all varying in degrees of information and communication tools incorporated such as mobile connectivity, blogging and photo/video sharing (Boyd and Ellison, 2007; Singh et al., 2012; Boyd, 2007).

Social networking extends beyond personal use to connect businesses to clients through prospective profile screening and video conference interviews. Academic research surrounding social networking is growing as user uptake increases. As social networking has increased in popularity, much attention has focused on the history of social networking. Pelling and White (2009) have researched the role of psychosocial variables in online social networking, while Boyd and Ellison (2007) identify how the cultures around social networking sites differ. Most social networking sites support the maintenance of pre-existing social networks, while others help strangers to connect based on political or religious views, or shared interests. As time continues and with the slow introduction of online purchases, social networking sites such as Facebook will become a platform for purchasing goods and services online more than it already is (MacMillan, 2009). This is likely to widen Facebook's user base due to the new shopping 'culture' that Facebook will have adopted.

Hargittai (2007) researched the differences between users and non-users of social networking sites and found that people with more experience with the internet are more likely to be a client of a social networking site. The low number of consumers present in the digital world contributes to differing consumer adoption rates (Hargittai, 2007). Cha (2009) touched on attitudes towards shopping on social networking web sites and found that people hold favourable attitudes towards social networking websites. They are easy to use; provide a lot of information and saves money. This study suggests consumers are increasing their use of social networking sites for shopping and reviewing and consequently social e-shopping is on the rise.

Singh et al. (2012) studied global media usage patterns to develop insights into how users of social networking sites differ, between specific countries, for business and personal use. Social media usage is not consistent throughout the world and there are differences as to how social media is being used, created and shared between cultures. Social networking from a business perspective means firms are able to control social media to create brand communities, gain consumer insights, enhance product and brand awareness, reduce service costs and optimise overall marketing communication efforts (Weinberg, 2009).

\section{Facebook}

A prominent theme over the past decade, from the increasing academic research, is the salience and effect of trust when it comes to taking and using advice from Facebook. Facebook users have acknowledged they trust the site and are more willing to share information than on other social networking sites such as MySpace (Dwyer et al., 2007). The recognition of trust from users is an important element for consumers when using social plug-ins, such as reading reviews and posting comments. 
The typical Facebooker is approaching adulthood and is between the ages of 18 and 24. The consumers within this segment are looking for independence and peers take a more prominent role in their life more so than their family. Consequently, Bumgarner (2007) identifies this segment of people to be relying on their network of friends for support, to take on the role of their surrogate family, hence the heavy use of Facebook. In 2012, only 48\% of users were categorised in this age bracket, thus Facebook's age group appeal is widening. More recently, Nelson-Field et al. (2012) recognises Facebook's potential to reach one third of the world's population, and so Facebook is becoming an increasingly important tool for marketers. Bujega (2006) points out that consumers have embraced and praised Facebook for the degree of control they have as individuals, however this has empowered marketers and advertisers with the most direct window into consumers psyche and buying habits that they have ever had. Consequently, it is becoming increasingly important, for research to gain deeper insights into Facebook, for marketing managers.

Ellison, Steinfeld and Lampe (2007) examined the relationship between the use of Facebook and the formation and maintenance of networks within and between Facebook. They clearly identified that the use of Facebook helps to build networks in online and offline contexts. Bumgarner (2007) and Park, Kee and Valenzuela (2009) examine the main use and gratification derived from using Facebook. The main reasons identified were to keep in touch with old friends and to intensify relationships that were formed offline, such as with classmates. However, among college students Facebook's main use is for the facilitation of gossip and discussion which highlights the importance of electronic word-of-mouth for businesses using Facebook. Facebook has become a platform where consumers can present their own views about products, life and 'what's on their mind'. As social networking site (SNS) shopping is still in its early days the shopping aspect of Facebook has not been adequately researched or identified as a major reason for Facebook use (Harris and Dennis, 2011).

Poynter (2008) examined how Facebook is changing traditional methods by using interactions such as 'Facebook polling', which enables quick answers to simple questions. Firms and researchers are able to create a question, specify a sample size, pay a small fee and have the results appear in their Facebook account a few hours later. This recognises Facebook's potential to reach consumers and the importance of Facebook as a tool for firms. Along with this, Facebook is also being used by nonprofit organisations. For-profit organisations have mainly used Facebook to help launch products and strengthen their existing brands, however little is known about non-profit organisations and Facebook. Waters, Burnett, Lamm, and Lucas (2009) acknowledge that non-profit organisations are present on Facebook but not actively using the interactive features. However, as there is no social networking handbook, they are learning through active participation. Facebook has even created an application to help non-profit firms fundraise with applications such as Causes, which allows individuals to donate to a registered organisation and recruit others to support the cause.

Viswanath, Mislove, Cha, and Gummad (2009) investigated the evolution of activity between users on Facebook and the strength of social ties over time. Only 30\% of Facebook interactions between pairs of people consistently run from one month to another. Facebook mechanisms such as birthday reminders facilitate much of this on- 
going activity. This is evidence that Facebook users make use of the social plug-ins Facebook has. More recently, Nelson-Field et al. (2012) investigated how valuable Facebook's reach was as a media platform. It appears heavy buyers of brands tend to be 'fans' of businesses' pages rather than light buyers, emphasising the importance of utilising Facebook in addition with other media vehicles.

The pitfalls of Facebook have been identified by Jain (2009), Dwyer et al. (2007) and Boyd (2008). These articles emphasise the lack of privacy on Facebook. Users are able to send 'friend requests' to people they have no prior association with and employers can 'stalk' potential employees before they are hired. Users have the ability to view photographs and personal messages between friends of people they don't really know. However, since the introduction of Facebook's 'newsfeed' in 2006, where friends' activity is listed as soon as users sign in, privacy settings have been put in place. Consequently, it is likely consumers have more trust within Facebook since then.

In 2008, Facebook introduced Facebook Connect, a social plug-in that allows retailers to have a Facebook log-in window on their website. By 2009, 43\% of online retailers had incorporated this gadget and, 31\% more planned to use it by 2010 (MacMillan, 2009). Facebook Connect allows shoppers who are logged into Facebook to see an item they want to buy and by simply clicking a 'share to Facebook' button send a photo and product details to their profiles and newsfeeds for their friends to see. Friends can share their opinion about the product or give recommendations. These comments and photos can pop up months later when friends are looking for similar information and consequently this Facebook feedback continues to influence friends in their purchasing environment. Facebook Connect also shows Facebook profile pictures of the Facebook users who have already visited the site and whom are your friends. Facebook Connect makes e-commerce more like traditional means of shopping. This social plug-in makes consumers feel like they're still going to the mall with their friends, as they can comment, like, and share their thoughts on the product. Facebook Connect allow customers to feel like they're getting the 'social experience' as in traditional shopping by connecting with friends and sharing opinions.

Tong, Van Der Heide, Langwell and Walther (2008) explored the effect of one feature of Facebook; the number of friends a user is purported to have. The authors tested whether there is an upper limit to the number of relationships an individual can credulously support. The results showed a curvilinear relationship between the number of friends, and others' perception of social attractiveness. Back et al. (2010) follows upon this chain of thought to research whether Facebook profiles actually reflect accurate impressions of the profile owner. It was identified that Facebook profiles are consistent with the 'extended life theory', that consumers use social networking sites to communicate their real personality (Back et al., 2010). Therefore, Facebook is a platform where consumers express and communicate their real personality and this is why it is such a popular platform.

MacMillan (2009) noted that Facebook lacked online payment options but was in the process of getting one with the help of PayPal. This would allow Facebook to collect fees from sellers for transactions performed within the network and would provide a revenue source based on how well retail and social media have been mixing. 
Nowadays the likes of Malaysian Airlines, Avon and Delta Airlines allow you to make a purchase without leaving Facebook (Harris and Dennis, 2011; MacMillan, 2009). Smaller businesses post photos of items for sale which require the potential buyer to post a 'SOLD' message in the comment line and then to 'private mail' the store to complete the purchase. This process enables buyers to review consumer feedback and see how many people are interested in the items. Customers are also able to post feedback and 'like' the item. To finalise the transaction the seller returns an email stating the exact price and where to deposit the money.

In conclusion, academic press yield rich insights into online purchase decisions, social networking and Facebook development, usage and diffusion. However this review highlighted some gaps in the literature pertaining consumers use and effect of social plug-ins and the prospective future of Facebook as an online shopping platform. This present stud extends the scope of Facebook research and differs from past surveys as it focuses on Facebook social plug-ins influence on consumers' purchase decisions, presenting insights into marketers' use of their Facebook page.

\section{Research Problem}

Social networking sites (SNS) are becoming an important medium for retail sales and consumer-to-consumer interaction. In addition to this, Facebook is becoming an increasingly important tool for consumers and firms alike. The possibility that Facebook will become an online shopping tool has generated interest in social networked applications and activities that can influence consumer purchase intention. However there has been little research that investigates whether SNS applications such as the like, sharing, posting and check-in capabilities on Facebook influence a consumer's intention to purchase a product through the Facebook platform. Facebook is today's most influential social networking site in the world; heightening the importance of understanding Facebook's applications and user activities (jrplaza, 2012; Nelson-Field et al., 2012). Increased understanding will enable marketing managers to engage with customers' better online, and help target their marketing communications strategy more efficiently. Thus it is of interest to examine the influence of Facebook social applications on consumers purchase intention. Consequently, the research question is; "do Facebook social applications have an influence on consumers purchase decision?”

\section{Research Objectives}

1. To better understand social network applications and activities that influence purchase intention

2. To prioritise these factors according to their influence on purchase decision

\section{Conceptual model and hypotheses Development}

\section{Likes}

The Facebook 'like' button function allows consumers to share pages from the website and/or company concerned back to the consumers Facebook profile with one click (Harris and Dennis, 2011). By 'liking' a page the user has voluntarily opted in to on-going communication with the owner of that page. Firms can create Facebook 
pages and subsequently encourage Facebook users to become "fans" of these pages by clicking the 'like' button on the page. Once this page has been 'liked', the user receives business updates and the ability to observe other fans activity within that business page through their personal newsfeed (Nelson-Field et al., 2012). Consequently, advertisements of new items, discounts, recommendations and reviews by others can and will be seen by the user. Therefore:

\section{$H_{1}$ : The number of "likes" a page of interest or item of interest receives positively influences consumer purchase intention.}

\section{Friends' Likes}

Harris and Dennis (Harris and Dennis, 2011) noted that shopping online and shopping through social networks (social e-shopping) were emerging, but two years on it is likely consumers are participating in purchases through social networks; trusting their friends recommendations through Facebook. Google is the search engine of choice, however information from friends is trusted more and consumers are more likely to purchase products or services that their friends have recommended. Therefore:

$\mathrm{H}_{2}$ : The more a consumer's Facebook friends have liked a page or product positively influences the consumer purchase decision.

\section{Location based check-in service}

Consumers can "check-in" through the Facebook "Places" application when they are at retail locations such as restaurants, fashion stores and services and share their location with friends. Many retailers have extended the Places mobile feature with a "Deals" application which provides incentives to check-in by offering discounts on purchases. This application can replace traditional coupons and loyalty cards (Slutsky, 2010). This application increases word of mouth and local knowledge, and also allows retailers to reach potential consumers. This is a relatively new application on Facebook and leads to the third hypothesis:

$\mathrm{H}_{3}$ : Location based 'check-in' services (such as Places) positively influences consumers purchase intention.

\section{Comment posting}

Facebook allows users to leave short comments; this information is displayed to the user's network of friends in real time via their newsfeed (Debatin et al., 2009). Placing a 'comment' and writing a review of a product or service is electronic word of mouth; defined as '...customers shar[ing] opinions and experiences with, goods and services, with a multitude of other consumers' (Hennig-Thurau et al., 2004). It can influence choices and provide advertising for the selected business involved. When consumers log into Facebook to find information about products and services, the 'comment' feature may influence consumers purchase intention. The effect of friends and other users 'posting' comments on purchase decision has not been widely researched and leads to the fourth hypothesis: 
$\mathrm{H}_{4}$ : Friends and other users 'posting' comments on goods and services positively influence consumer purchase intention.

\section{Sharing}

Facebook allows consumers to 'share' product/service or business pages that they think are important and relevant. Every 20 minutes one million links are shared on Facebook (Branckaute, 2010). If a link to a particular page, product or discount is shared several times on Facebook, it will appear in the recommendations list and newsfeeds, highlighting how many people have shared it. If people post images of products or the page of the business itself as their status, this will appear in their newsfeed. It will be visible to all users' friends whom are then able to comment and further share the link to their friends, which leads to the fifth hypothesis:

$\mathrm{H}_{5}$ : Friends and businesses 'sharing' pages, products or services positively influence consumer purchase intention

\section{Figure 1: Conceptual model}

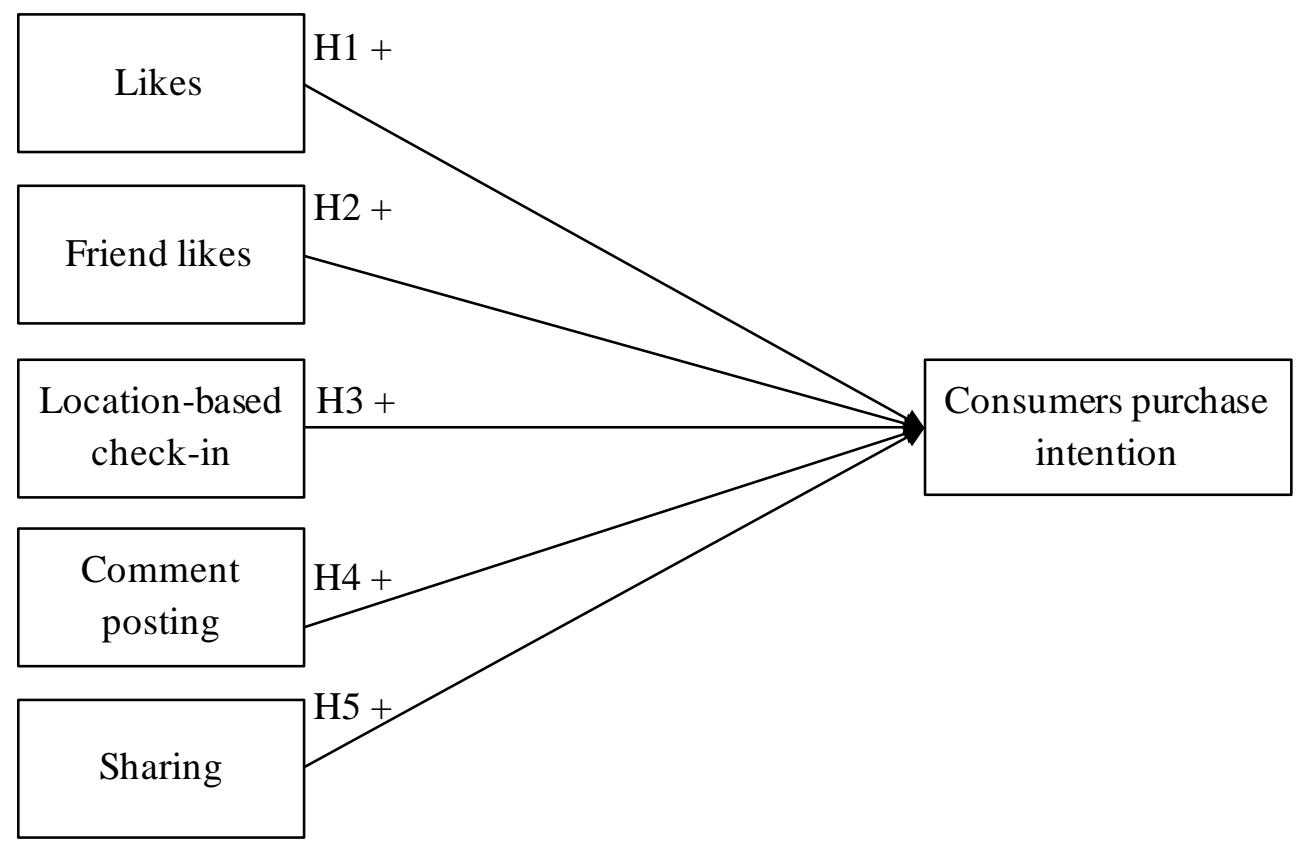

\section{Methodology}

Participants were given a link to the survey through Facebook and asked to complete the questionnaire. A public Facebook event was created to reach a base of users. Once these users had completed the survey, the event with the link would come up on their newsfeeds from which other users could then participate in the survey. This snowball sampling technique was used to help find appropriate subjects, in this case Facebook users, who are otherwise hard to locate, as it was vital for respondents to be Facebook users. This chain referral process allows respondents to be identified in a way that would have been hard if other sampling techniques were used (Hair et al., 2010). 
The likes construct, friends' likes construct, location based check-in service construct, comment posting construct and sharing construct were measured for attention, use and interest. Use was measured based upon a scale by Ko, Cho and Roberts (2005), while both the attention and interest items were newly created from the literature, since these aspects of SNS applications research are relatively new. The Ko, et al. original scale $(\alpha=.78)$ measures how much a person would be likely to interact with a website in the future due to its content related usefulness. This scale was adapted from the future tense to the present tense, since the focus of the current research is how SNS (Facebook) users are presently using these social plug-in applications. Respondents had to rate how much attention they pay to the social plug-in and how much interest they have in each of the social plug-ins. Five-point Likert scales were employed for participants to rate each item, anchored with $1=$ Never, $5=$ Always, see Table 2.

The consumers purchase intention construct was adapted from Baker and Churchill's (1977) purchase intention scale, which measured the physical attractiveness of models in advertising, to measure consumers' intention to purchase products through Facebook rather than purchase a particular product. The scale measured consumer's cognitive, affective, and conative components of a person's evaluation. This study utilises a 5-point Likert scale with anchors 1 = definitely not and $5=$ yes, definitely.

\section{Findings}

Data was collected over a three week period in August 2012. Participants took part through an online survey with an average time of three minutes to complete. This survey yielded 216 usable respondents, from a total of 234, of which $75.5 \%$ of the 16 to 24 year olds log in to Facebook at least once daily and $87.0 \%$ of total respondents $\log$ in at least once daily, see Table 1 . The survey consisted of 18 questions with an additional three demographic questions for age, gender and work experience. Eightyfour per cent of the sample was between the ages of 16 and 24, with 73 per cent female and 27 per cent male. Seventy-nine per cent of respondents worked either full or part time. The data was analysed using SPSS version 18 software.

Table 1: Frequency of respondent Facebook log in by age

\begin{tabular}{lccccc}
\hline & \multicolumn{7}{c}{ Age } \\
& $16-24$ & $25-40$ & $41-65$ & $65+$ & Total \\
\hline Less than once per day & 19 & 2 & 6 & 1 & 28 \\
Once per day & 37 & 3 & 2 & 0 & 42 \\
More than once daily & 126 & 16 & 4 & 0 & 146 \\
\hline Total & 182 & 21 & 12 & 1 & 216 \\
\hline
\end{tabular}

\section{Measurement Scales}

Attention, use and interest items were newly developed from the literature to measure the likes, friends' likes, location based check-in, comment posting and sharing constructs (Ko et al., 2005). Each construct demonstrated acceptable convergent validity (loadings $>.70)$ and reliability $(\alpha>.60)$, see Table 2 (Hair et al., 2010). 
Table 2: Scale items, factor loadings, Cronbach’s alpha, and variance explained

\begin{tabular}{|c|c|c|c|}
\hline Scale items & \multirow{2}{*}{ Loadings } & \multirow{2}{*}{$\alpha$} & \multirow{2}{*}{$\begin{array}{c}\text { Variance } \\
\text { explained }\end{array}$} \\
\hline Likes & & & \\
\hline I pay attention to the number of likes a product has & .883 & \multirow{3}{*}{0.834} & \multirow{3}{*}{$75.9 \%$} \\
\hline I use the like function to rate products & .824 & & \\
\hline The amount of likes for a product interests me & .903 & & \\
\hline \multicolumn{4}{|l|}{ Friend likes } \\
\hline $\begin{array}{l}\text { I pay attention to my Facebook friends liking } \\
\text { products and business pages }\end{array}$ & .859 & \multirow{3}{*}{0.851} & \multirow{3}{*}{$77.1 \%$} \\
\hline $\begin{array}{l}\text { I click on photos of products or business pages that } \\
\text { show up on my homepage from my friends liking } \\
\text { them }\end{array}$ & .869 & & \\
\hline $\begin{array}{l}\text { I am interested if my friends have liked the product } \\
\text { or business page }\end{array}$ & .906 & & \\
\hline \multicolumn{4}{|l|}{ Location based check-in } \\
\hline $\begin{array}{l}\text { I pay attention to my Facebook friends who 'check- } \\
\text { in' to stores }\end{array}$ & .889 & \multirow{3}{*}{0.844} & \multirow{3}{*}{$76.5 \%$} \\
\hline $\begin{array}{l}\text { I use the Facebook 'check-in' location based } \\
\text { application }\end{array}$ & .858 & & \\
\hline I click on the location my friends have checked into & .877 & & \\
\hline \multicolumn{4}{|l|}{ Comment posting } \\
\hline $\begin{array}{l}\text { I pay attention to the review comments posted on } \\
\text { Facebook }\end{array}$ & .828 & \multirow{3}{*}{0.818} & \multirow{3}{*}{$73.5 \%$} \\
\hline I use Facebook to post reviews & .867 & & \\
\hline $\begin{array}{l}\text { Posting review comments really interests me to } \\
\text { make my purchase }\end{array}$ & .876 & & \\
\hline \multicolumn{4}{|l|}{ Sharing } \\
\hline $\begin{array}{l}\text { I pay attention to what products and pages are } \\
\text { 'shared' on Facebook }\end{array}$ & .882 & \multirow{3}{*}{0.833} & \multirow{3}{*}{$75.4 \%$} \\
\hline I 'share' products and pages on Facebook & .806 & & \\
\hline It interests me when pages are 'shared' & .913 & & \\
\hline \multicolumn{4}{|l|}{ Purchase intention } \\
\hline $\begin{array}{l}\text { Would you like to try a product recommended on } \\
\text { Facebook? }\end{array}$ & .867 & \multirow{3}{*}{0.860} & \multirow{3}{*}{$78.4 \%$} \\
\hline $\begin{array}{l}\text { Would you buy this product if you happened to see } \\
\text { it on Facebook? }\end{array}$ & .927 & & \\
\hline $\begin{array}{l}\text { Would you actively seek out this product on } \\
\text { Facebook to purchase it? }\end{array}$ & .861 & & \\
\hline
\end{tabular}

\section{Hypothesis Testing}

In combination, likes, friends' likes, use of location based check-in, comment posting and sharing accounted for a significant $42.3 \%$ of the variability in consumers purchase intention, $\mathrm{R}^{2}=0.423$, adjusted $\mathrm{R}^{2}=.409, F(5,209)=30.62, p<.001$. As Table 3 shows, friends' likes has the largest impact on consumers purchase intention with a $\beta$ value of .231 ( $p=.004)$. Comment posting has no significant influence on consumer purchase intention $(\beta=.056, p=.424)$. Consequently, hypothesis $1,2,3$ and 5 are supported while hypothesis 4 is not supported. 
Table 3: Multiple regression analysis results

\begin{tabular}{l|c|c|c}
\hline Hypothesis of likes positively effects purchase & $\boldsymbol{\beta}$ & $\boldsymbol{t}$ & $\boldsymbol{p}$ \\
\hline $\begin{array}{c}\mathrm{H}_{1}: \text { Number of } \\
\text { intention }\end{array}$ & 2.782 & 0.006 \\
\hline $\begin{array}{c}\mathrm{H}_{2}: \text { Number of friends' likes positively effects } \\
\text { purchase intention }\end{array}$ & 0.231 & 2.873 & 0.004 \\
\hline $\begin{array}{c}\mathrm{H}_{3}: \text { Use of location based check-in service positively } \\
\text { effects purchase intention }\end{array}$ & 0.177 & 2.708 & 0.007 \\
\hline $\begin{array}{l}\mathrm{H}_{4}: \text { Posting of comments positively effects purchase } \\
\text { intention }\end{array}$ & 0.056 & 0.801 & 0.424 \\
\hline $\mathrm{H}_{5}$ : Sharing links positively effects purchase intention & 0.153 & 2.077 & 0.039 \\
\hline
\end{tabular}

\section{Discussion}

It appears from this study that Facebook can play an important role in consumers purchase intention. The likes construct was not confined to current Facebook friends, these 'likes' could have been from anyone, anywhere, in the world yet still had the second highest influence on consumer purchase intention. This result supports the focus group quote from Harris and Dennis (2011) that if consumers "see 40,000 Facebook 'likes' - yes, I would click through..., I like to see what others have said... anybody, not just people I know". The results of this study support the fact that consumers are influenced by the Facebook 'like' application and reinforce the importance of firms' active presence on Facebook.

The Facebook "friends like" application and activity was the most influential on consumer purchase intention. This is understandable given that one primary use of Facebook it to track and take notice of friends' activity (Ellison et al., 2007). However it is most likely the use of "friend likes" as a proxy for the trust and risk aversion aspects of online purchase intention which are most relevant (Lee and Tan, 2003; Goode and Harris, 2007; Harris and Goode, 2010).

The significant influence of "friends like", "check-in" and "sharing" activities on purchase decision-making confirms a recent Nielson report (2010) and Harris and Dennis (2011) study which indicates consumers trust their friends and family more than any other source of information about products and services. Thus when friends use Facebook's 'like', 'check-in', and 'share' interaction, consumers take notice of the product or firm which consequently influences purchase intention.

Anonymous comment postings do not significantly affect consumer purchase intention $\left(\mathrm{H}_{4}\right)$.This result is consistent with Harris and Dennis' (2011) research findings; that friend reviews are trusted more than anonymous reviews, and provides an explanation why respondents did not associate general Facebook user's comments to their purchase decision. However the findings from this study contradict Ewing (2009) and Fournier and Avery's (2011) view that consumers actually take notice of people sharing their experiences through Facebook. It would be beneficial to test the impact of friends' comments and non-friends comments on purchase intention. 


\section{Managerial Implications}

Consumers are increasingly taking notice of these Facebook applications which influence their purchase decision. Currently, many retailers still lack any real integration between their own web channel and social media despite the proliferation of 'like' buttons. However, as marketers realise the potential for Facebook to become an a shopping platform they need to develop appropriate interdepartmental staff training for improved engagement with Facebook as a social medium and potential sales channel.

\section{Limitations}

This study was primarily concerned with the like button, location based check-in service, posting of comments and the share button on Facebook. Although the majority of the respondents are Facebook savvy, due to the fact many of these Facebook applications are relatively new not all respondents may be aware of their use or how to use them. Future research should focus on the use, privacy and trust aspects of SNS with respect to purchase intent and behaviour.

\section{References}

Back, M., Stopfer, J., Vazire, S., Gaddis, S., Schmukle, S., Egloff, B. \& Gosling, S. (2010), "Facebook profiles reflect actual personality, not self-idealization". Psychological science, vol. 21, no. 3, pp. 372-374.

Baker, M. J. \& Churchill, G. A., Jr. (1977), "The impact of physically attractive models on advertising evaluations". Journal of Marketing Research, vol. 14, no. 4, pp. 538-555.

Boyd, D. M. (2007), "Why youth (heart) social network sites: The role of networked publics in teenage social life". In: Youth, Identity, and Digital Media. Buckingham, D. (Ed.). (Cambridge, MA), MIT Press, pp. 119-142.

Boyd, D. M. (2008), "Facebook's privacy trainwreck: Exposure, invasion, and social convergence". Convergence: The International Journal of Research into New Media Technologies, vol. 14, no. 1, pp. 13-20.

Boyd, D. M. \& Ellison, N. B. (2007), "Social network sites: Definition, history, and scholarship". Journal of Computer-Mediated Communication, vol. 13, no. 1, pp. 210230 .

Branckaute, F. (2010). Facebook statistics: The numbers game continues [Web blog post]. Retrieved from http://www.blogherald.com/2010/08/11/facebook-statistics-thenumbers-game-continues/

Bugeja, M. J. (2006). Advice: Facing the Facebook. The Chronicle of Higher Education. Retrieved from Chronicle.com website: http://chronicle.com/article/Facing-theFacebook/46904

Bumgarner, B. A. (2007). You have been poked: Exploring the uses and gratifications of Facebook among emerging adults. First Monday, 12(11). Retrieved from doi:10.5210/fm.v12i11.2026 
Cha, J. (2009), "Shopping on social networking Web sites: Attitudes toward real versus virtual items". Journal of Interactive Advertising, vol. 10, no. 1, pp. 77-93.

Clark, N. (2010). Facebook overtakes Google. The Independent. Retrieved from http://www.independent.co.uk/life-style/gadgets-and-tech/news/facebookovertakes-google-1923102.html

Debatin, B., Lovejoy, J. P., Horn, A.-K. \& Hughes, B. N. (2009), "Facebook and online privacy: Attitudes, behaviors, and unintended consequences". Journal of ComputerMediated Communication, vol. 15, no. 1, pp. 83-108.

Dwyer, C., Hiltz, S. R. \& Passerini, K. (2007), Trust and privacy concern within social networking sites: A comparison of Facebook and MySpace. IN Hoxmeier, J. A. \& Hayne, S. (Eds.) 13th Americas Conference on Information Systems (AMCIS 2007): Reaching New Heights. Keystone, Colorado, Curran Associates, pp. Paper 339.

Ellison, N. B., Steinfield, C. \& Lampe, C. (2007), "The benefits of Facebook 'friends:' Social capital and college students' use of online social network sites". Journal of ComputerMediated Communication, vol. 12, no. 4, pp. 1143-1168.

Ewing, M. T. (2009), "Integrated marketing communications measurement and evaluation". Journal of Marketing Communications, vol. 15, no. 2-3, pp. 103-117.

Fournier, S. \& Avery, J. (2011), "The uninvited brand". Business Horizons, vol. 54, no. 3, pp. 193-207.

Goode, M. M. H. \& Harris, L. C. (2007), "Online behavioural intentions: an empirical investigation of antecedents and moderators". European Journal of Marketing, vol. 41, no. 5/6, pp. 512-536.

Hair, J. F., Jr., Black, W. C., Babin, B. J. \& Andersen, R. E. (2010), Mutilvariate data analysis: A global perspective, Pearson Prentice Hall, Upper Saddle River, NJ.

Hargittai, E. (2007), "Whose space? Differences among users and non-users of social network sites". Journal of Computer-Mediated Communication, vol. 13, no. 1, pp. 276-297.

Harris, L. \& Dennis, C. (2011), "Engaging customers on facebook: Challenges for e-retailers". Journal of Consumer Behaviour, vol. 10, no. 6, pp. 338-346.

Harris, L. C. \& Goode, M. M. H. (2010), "Online servicescapes, trust, and purchase intentions". Journal of Services Marketing, vol. 24, no. 3, pp. 230-243.

Hennig-Thurau, T., Gwinner, K. P., Walsh, G. \& Gremler, D. D. (2004), "Electronic word-ofmouth via consumer-opinion platforms: What motivates consumers to articulate themselves on the Internet?". Journal of Interactive Marketing, vol. 18, no. 1, pp. 3852.

Jain, S. H. (2009), "Practicing medicine in the age of Facebook". The New England Journal of Medicine, vol. 361, no. 7, pp. 649-51.

jrplaza. (2012). 10 of the most influential social networking sites [Web blog post]. Retrieved from http://always10list.com/2012/05/10-of-the-most-influential-social-networking$\underline{\text { sites/ }}$ 
Ko, H., Cho, C.-H. \& Roberts, M. S. (2005), "Internet uses and gratifications: A structural equation model of interactive advertising". Journal of Advertising, vol. 34, no. 2, pp. 57-70.

Lee, K. S. \& Tan, S. J. (2003), "E-retailing versus physical retailing: A theoretical model and empirical test of consumer choice". Journal of Business Research, vol. 56, no. 11, pp. 877-885.

MacMillan, D. (2009). Facebook banks on a little help from its friends. Bloomberg Businessweek. Retrieved from Businessweek.com website: http://www.businessweek.com/magazine/content/09 43/b4152048040939.ht $\underline{\mathrm{m}}$

Nelson-Field, K., Riebe, E. \& Sharp, B. (2012), "What's not to "like?" Can a Facebook fan base give a brand the advertising reach it needs?". Journal of Advertising Research, vol. 52, no. 2, pp. 262-269.

Nielsen Newswire. (2010). Friending the social consumer Retrieved 2 October, 2012, from $\quad$ http://www.nielsen.com/us/en/newswire/2010/friending-the-socialconsumer.html

Park, N., Kee, K. F. \& Valenzuela, S. (2009), "Being immersed in social networking environment: Facebook groups, uses and gratifications, and social outcomes". CyberPsychology \& Behavior, vol. 12, no. 6, pp. 729-733.

Pelling, E. L. \& White, K. M. (2009), "The theory of planned behavior applied to young people's use of social networking Web sites". CyberPsychology \& Behavior, vol. 12, no. 6, pp. 755-759.

Poynter, R. (2008), "Facebook: the future of networking with customers". International Journal of Market Research, vol. 50, no. 1, pp. 11-12.

Rousseau, D. M., Sitkin, S. B., Burt, R. S. \& Camerer, C. (1998), "Not so different after all: a cross-discipline view of trust". Academy of Management review, vol. 23, no. 3, pp. 393-404.

Singh, N., Lehnert, K. \& Bostick, K. (2012), "Global social media usage: Insights into reaching consumers worldwide". Thunderbird International Business Review, vol. 54, no. 5, pp. 683-700.

Slutsky, I. (2010). Facebook ads provide 'Deals' for local merchants, marketers Retrieved 4 July, 2013, from http://adage.com/article/digital/facebook-deals-service-takesfoursquare-groupon/146878/

Tong, S. T., Van Der Heide, B., Langwell, L. \& Walther, J. B. (2008), "Too much of a good thing? The relationship between number of friends and interpersonal impressions on Facebook". Journal of Computer-Mediated Communication, vol. 13, no. 3, pp. 531549.

van der Heijden, H. \& Verhagen, T. (2002), Measuring and assessing online store image: a study of two online bookshops in the Benelux. IN Sprague, R. H., Jr. (Ed.) System Sciences, 2002. HICSS. Proceedings of the 35th Annual Hawaii International Conference. Big Island, HI, The Printing House, pp. 2639-2646. 
van der Heijden, H., Verhagen, T. \& Creemers, M. (2003), "Understanding online purchase intentions: contributions from technology and trust perspectives". European Journal of Information Systems, vol. 12, no. 1, pp. 41-48.

Viswanath, B., Mislove, A., Cha, M. \& Gummadi, K. P. (2009), On the evolution of user interaction in Facebook. Proceedings of the 2nd ACM workshop on Online social networks. Barcelona, Spain, ACM, pp. 37-42.

Waters, R. D., Burnett, E., Lamm, A. \& Lucas, J. (2009), "Engaging stakeholders through social networking: How nonprofit organizations are using Facebook". Public Relations Review, vol. 35, no. 2, pp. 102-106.

Weinberg, T. (2009), The new community rules: Marketing on the social Web, O'Reilly Media, Sebastopol, CA.

Weisberg, J., Te'eni, D. \& Arman, L. (2011), "Past purchase and intention to purchase in ecommerce. The mediation of social presence and trust". Internet Research, vol. 21, no. 1, pp. 82-96. 